\title{
The effect of green tea extract supplementation on exercise- induced oxidative stress parameters in male sprinters
}

\author{
Ewa Jówko • Barbara Długołęcka • Beata Makaruk • \\ Igor Cieśliński
}

Received: 30 January 2014/ Accepted: 1 August 2014/Published online: 14 August 2014

(C) The Author(s) 2014. This article is published with open access at Springerlink.com

\begin{abstract}
Background Although research suggests that antioxidant supplementation can protect against exercise-induced muscle damage and oxidative stress, also delayed postexercise muscle recovery and hindered adaptation to training were reported in the supplemented athletes.

Purpose The purpose of the study was to evaluate the effects of green tea extract (GTE) supplementation on selected blood markers of oxidative stress and muscle damage in sprinters during preparatory phase of their training cycle.

Methods Sixteen sprinters participated in a double-blind, randomized, placebo (PL)-controlled crossover study, including two 4-week treatment periods with PL and GTE (980 mg polyphenols daily). The sprinters performed two repeated cycle sprint tests (RST; $4 \times 15 \mathrm{~s}$, with 1-min rest intervals), after PL and GTE supplementation. Blood was sampled before (at rest), 5 min after RST, and after the 24-h recovery. The activities of superoxide dismutase (SOD) and glutathione peroxidase were measured in erythrocytes, and total polyphenols, total antioxidant capacity (TAC), uric acid (UA), albumin (AL), malondialdehyde (MDA), and creatine kinase (CK) were determined in blood plasma.
\end{abstract}

\footnotetext{
E. Jówko $(\varangle) \cdot$ B. Długołęcka

Department of Physiology and Biochemistry, Faculty of Physical Education and Sport in Biala Podlaska, Jozef Pilsudski

University of Physical Education in Warsaw, Akademicka 2,

21-500 Biala Podlaska, Poland

e-mail: ewa.jowko@awf-bp.edu.pl

B. Makaruk · I. Cieśliński

Faculty of Physical Education and Sport in Biala Podlaska, Jozef Pilsudski University of Physical Education in Warsaw, Akademicka 2, 21-500 Biala Podlaska, Poland
}

Results Repeated cycle sprint test performed after PL induced an increase in MDA, TAC, and SOD. Moreover, an increase in UA, AL, and CK was observed after RST irrespective of experimental conditions (PL, GTE). Supplementation with GTE caused an increase in total polyphenols and TAC at rest, and a decrease in MDA and SOD after RST. No significant changes in sprint performance were noted after GTE, as compared to PL.

Conclusions Supplementation with GTE prevents oxidative stress induced by RST in sprinters. Furthermore, GTE supplementation does not seem to hinder training adaptation in antioxidant enzyme system. On the other hand, neither prevention of exercise-induced muscle damage, nor an improvement in sprint performance is noted after GTE administration.

Keywords Green tea extract - Oxidative stress . Sprinters $\cdot$ Repeated sprint test

\section{Introduction}

Both strenuous long-term and short-term anaerobic exercises were reported to enhance the generation of reactive oxygen species (ROS) by cells, which may lead to oxidative stress and cellular damage $[1,2]$. On the other hand, ROS not only cause cellular damage, but also play an important role in modulation of cell signaling involved in training adaptations at the cellular level [3,4]. One of these adaptations is the activation of redox-sensitive signal transduction pathway and enhancement in gene expression of antioxidant enzymes [4]. Training-induced up-regulation of endogenous antioxidants has been established to reduce the risk of cellular injury during acute exercise [1]. However, despite having increased superoxide dismutase (SOD) 
activity, athletes exhibit decreased total antioxidant status of plasma and elevated markers of lipid peroxidation and muscle damage as compared to sedentary subjects [5].

There is emerging evidence suggesting that ROS play an important physiological role in supporting the recovery process and protecting the cells from future damage [6]. Several studies revealed that antioxidant supplements may hinder the beneficial cell adaptations to exercise [7-9]. Moreover, delayed muscle recovery after acute exercise, as a result of 4-week antioxidant supplementation, was also reported [10]. However, these observations regarding the impaired training adaptation after antioxidant supplementation were not confirmed by other studies [11, 12]. Thus, the practice of taking antioxidants before exercise is recently a subject of ongoing debate and perhaps should be re-evaluated [13, 14].

Tea catechins, polyphenols with flavonoid structure, belong to chemical substances with strong antioxidant properties [15]. In our study of previously untrained men [16], the 4-week green tea extract (GTE) supplementation enhanced the total antioxidant potential of plasma and prevented oxidative damage induced by both short-term muscular endurance test and 4-week strength training. In another study [17], the protective effect of green tea beverages on oxidative stress and muscular damage parameters was also observed in weight-trained men. However, there is no published research on the effects of GTE supplementation on oxidative stress and muscle damage parameters in trained sprinters. It has been suggested that increased production of ROS during short-term, high-intensity exercise is mostly caused by the activation of xanthine oxidase (XO) pathway [18, 19]. Increases in both serum XO activity and serum concentration of uric acid (UA), i.e., the end product of XO pathway, have been reported after repeated sprint exercises as support of that thesis [20]. Correspondingly, the inhibition of XO (by allopurinol) has been reported to protect against cell damage induced by exhaustive exercise in humans [21]. On the other hand, when ROS production was prevented in rats, up-regulated expression of important enzymes associated with cell defense (like SOD) and adaptation to exercise were also abolished [22, 23]. Thus, it is interesting to investigate whether GTE supplementation can be beneficial for sprinttrained athletes during their habitual training schedule. The results of previous in vitro studies suggest that, apart from direct scavenging of ROS and chelating with metal ions [24], the antioxidant activity of tea catechins results from the inhibition of XO activity [25].

The aim of this study was to evaluate the effects of 4-week GTE supplementation on selected blood markers of oxidative stress [total antioxidant capacity (TAC), UA, albumin (AL), malondialdehyde (MDA), SOD, and glutathione peroxidase $(\mathrm{GPx})$ ] and muscle cell damage [creatine kinase $(\mathrm{CK})]$ in male sprinters during preparatory phase of their yearly training cycle.

\section{Materials and methods}

Subjects

Sixteen male sprinters from a university sport club (aged $21.6 \pm 1.5$ years; body weight $76.9 \pm 6.4 \mathrm{~kg}$; height $180.5 \pm 6.2 \mathrm{~cm} ;$ BMI $23.5 \pm 1.1 \mathrm{~kg} / \mathrm{m}^{2} ; \%$ body fat $11.8 \pm 2.5 \%$; training experience $4.4 \pm 1.4$ years), all students of physical education, volunteered for the study. The exclusion criteria were the use of tobacco products, alcohol consumption, recent surgery or illness, and use of any medicine or dietary supplements in 4 weeks prior to the study. The protocol of the study was approved by the local Bioethical Committee at the Academy of Physical Education in Warsaw, and the research was conducted in accordance with the principles stated in the Declaration of Helsinki.

\section{Experimental procedures}

The double-blind, randomized, placebo (PL)-controlled crossover study was conducted during preparatory phase of yearly training cycle (after transition period). The two 4-week treatment periods (during which half of the subjects received GTE and the other half PL, and vice versa) were separated by a 4 -week washout period. The duration of the washout period was selected based on the results of one previous study [26], in which 6-week supplementation with $800 \mathrm{mg}$ catechins daily was used. In that study, plasma catechin concentration returned to its baseline level after at least 2 weeks of washout period.

Both GTE and PL were administered in the form of dark gelatin capsules (Olimp Labs, Dębica, Poland), identical in appearance (i.e., size, shape, and color); the same dosage regimen was used (two capsules twice a day). One GTP capsule contained $250 \mathrm{mg}$ of standardized GTE $(245 \mathrm{mg}$ polyphenols, including $200 \mathrm{mg}$ catechins, among them $137 \mathrm{mg}$ epigallocatechin-3-galate) and additional substances (maltodextrin, microcrystalline cellulose, and magnesium stearate). Therefore, each participant was administered $980 \mathrm{mg}$ polyphenols daily. PL capsules contained microcrystalline cellulose, magnesium stearate, and maltodextrin instead of GTP. The compliance was measured by capsule counting. The participants who returned no more than $15 \%$ of their capsule dose were classified as "compliant".

At the end of each of the two 4-week treatment periods, the sprinters performed a repeated cycle sprint test (RST) 
on a cycle ergometer (Ergomedic 839E, Monark, Sweden). The test consisted of four consecutive 15 -s bouts $(4 \times 15 \mathrm{~s})$, each of them with base set according to the Wingate procedure and separated by 1-min rest intervals. The subjects were asked to cycle for $15 \mathrm{~s}$, as fast as possible, against a constant load (75 g/ $\mathrm{kg}$ body weight). The test was preceded by a 5-min warm-up with submaximal load, until the heart rate reached $130-150$ beats/min (Polar, Finland). The following exercise parameters were registered (Multi CykloErgometr MCE version 5.1) during each of four 15-s bouts: peak power $(\mathrm{W} / \mathrm{kg})$, mean power $(\mathrm{W} / \mathrm{kg})$, total work output $(\mathrm{J} / \mathrm{kg})$, and fatigue index $(\%)$. The tests were performed in the morning following 12-h overnight fast, at air temperature between 19 and $21{ }^{\circ} \mathrm{C}$ and with $40-60 \%$ relative humidity. The subjects were instructed to not perform hard physical training for $48 \mathrm{~h}$ and avoid drinking tea and caffeinated beverages within $24 \mathrm{~h}$ prior to each of the RSTs. The subjects were asked to refrain from any dietary supplements for the duration of the study.

\section{Dietary intake}

The participants were asked to not modify their diet for the duration of the study, except for refraining from consuming any products containing green tea and limiting the intake of caffeine-containing drinks to one cup per day. Moreover, they were asked to maintain a similar diet for both treatment periods. During both the first and the second treatment periods (during 7 days preceding each RST), the participants filled out a 3-day dietary record (covering 2 week days and 1 day of the week end). The amount of ingested foods was estimated with an aid of dedicated picture book [27]. The daily dietary intake of vitamins $\mathrm{C}$ and $\mathrm{E}$, beta-carotene, and selenium was calculated using Dietus software (based on national food tables) [28].

\section{Blood sampling}

Capillary blood samples were taken from a finger pulp, before the test and $3 \mathrm{~min}$ after completing the test. Venous blood samples were drawn into heparinized test tubes from the ulnar vein before completing the test (at rest), $5 \mathrm{~min}$ after completing the test, and following the 24-h recovery period. The venous blood was centrifuged (for $10 \mathrm{~min}$ at $3,000 \times g$ at a temperature of $4{ }^{\circ} \mathrm{C}$ ) to separate erythrocytes from plasma. Subsequently, erythrocytes were washed three times with a cold isotonic saline solution. Both erythrocytes and plasma were frozen and stored at $-80{ }^{\circ} \mathrm{C}$ until analysis.
Laboratory analysis

Capillary blood was assayed for the concentration of lactate, as well as for the parameters of acid-base equilibrium. The concentration of lactate was determined with a diagnostic cuvette kit (Dr. Lange, catalogue no. LKM 140, Germany) in a Miniphotometer Plus LP 20 (Hach Lange, Germany). An automated analyzer (OMNI-C analyzer, Roche Diagnostics, Austria) was used to measure the acidbase balance parameters in capillary blood: $\mathrm{pH}$ value, base excess, and anion gap, as well as hematocrit. According to the manufacturer, the intra-assay coefficients of variation for $\mathrm{pH}$ and hematocrit measurements were below 2.0 and $3.0 \%$, respectively.

Plasma concentrations of total polyphenols, UA, AL, and MDA were determined, along with TAC and the activity of CK. Erythrocytes were analyzed for the activity of SOD and GPx.

Analysis of total plasma polyphenols was performed using the Folin-Ciocatleau method, as described by Maskarinec et al. [29]. Gallic acid in ethanol served as the standard solution, and the results for total polyphenols were given as $\mu \mathrm{g} / \mathrm{ml}$ gallic acid equivalents (GE). The average intra-assay coefficient of variation (calculated for ten duplicated samples) was $7.8 \%$.

The total antioxidant capacity of plasma (TAC) to scavenge ABTS radicals was measured by a chromogenic method with commercially available kit (Cat. No. NX 2332, Randox, Crumlin, UK). Antioxidant capacity of samples was expressed as millimoles per liter of Trolox equivalents (6-hydroxy-2,5,7,8-tetramethylchroman-2-carboxylic acid). The average intra-assay coefficient of variation (calculated for ten duplicated samples) was $4.9 \%$.

Plasma UA and AL concentrations were determined with commercially available kits (Cat. No. K6580-200 and A6502-100, respectively; Alpha Diagnostics, USA). The average intra-assay coefficients of variation (calculated for ten duplicated samples) for UA and AL were 6.1 and $4.3 \%$, respectively.

The SOD and GPx activities in erythrocytes were determined with commercially available kits (RANSOD Cat. No. SD 125 and RANSEL Cat. No. RS 505, respectively; Randox, Crumlin, UK). The antioxidant enzyme activities were measured at $37{ }^{\circ} \mathrm{C}$ and expressed in $\mathrm{U} / \mathrm{g} \mathrm{Hb}$. Hemoglobin was assessed by a standard cyanmethemoglobin method, using a diagnostic kit (HG 1539; Randox, Crumlin, UK). The average intra-assay coefficient of variation (calculated for ten duplicated samples) for SOD, GPx, and $\mathrm{Hb}$ was 3.8, 6.9, and $2.9 \%$, respectively.

Plasma MDA levels were determined with a commercially available kit (LPO-586, OXIS Internatl., Portland, OR). Plasma CK activity was determined with the use of a diagnostic kit (Cat. No. C6512-100, Alpha Diagnostics, 
USA). The average intra-assay coefficient of variation (calculated for ten duplicated samples) for MDA and CK was 7.5 and $8.3 \%$, respectively. Due to the decreased plasma volume following exercise [30], plasma volume was corrected for post-exercise changes by considering the changes in hematocrit according to the Dill and Costill method [31].

\section{Statistical analysis}

Statistical analysis was performed with Statistica version 6.0 software package. Paired $t$ test was used to compare the results of the dietary survey and RST, and resting total plasma polyphenols levels documented after two 4-week treatment periods. The data regarding biochemical parameters were analyzed using 2 (treatment: PL and GTE) $\times 3$ (time points: at rest, $5 \mathrm{~min}$, and $24 \mathrm{~h}$ after completion of the test) factorial (two-way) ANOVA. If a significant time and treatment interaction was detected, the data within each treatment (at rest, 5 min post-exercise, and after 24-h of recovery) were analyzed and compared between treatments (PL and GTE) using the Bonferroni corrected paired $t$ test. The normal distribution of all dependent variables was confirmed with the Shapiro-Wilk test and visual inspection (quantile distribution plots). All values were reported as mean $\pm \mathrm{SEM}$. The level of statistical significance was set at $p<0.05$.

\section{Results}

Mean daily energy intake and intakes of vitamins $\mathrm{C}$ and $\mathrm{E}$, beta-carotene, and selenium in daily food rations of participants are presented in Table 1. No significant differences were found between PL and GTE treatments for any of the studied parameters. The diet was adequate in terms of the Polish Nutrition Society recommendations for physically active men [32]. The percentages of compliant were $100 \%$ for both GTE and PL (compliance rates for

Table 1 Daily intake of energy, vitamins C and E, beta-carotene, and selenium in sprinters $(n=16)$ after 4-week supplementation with placebo (PL) or green tea extract (GTE)

\begin{tabular}{|c|c|c|}
\hline & PL & GTE \\
\hline Energy (kcal) & $4,072 \pm 120$ & $3,911 \pm 105$ \\
\hline Vitamin C (mg) & $99 \pm 3$ & $95 \pm 2$ \\
\hline Vitamin E $(\mathrm{mg})^{\mathrm{a}}$ & $9.6 \pm 0.3$ & $9.1 \pm 0.6$ \\
\hline Beta-carotene $(\mu \mathrm{g})$ & $3,715 \pm 105$ & $3,749 \pm 99$ \\
\hline Selenium $(\mu \mathrm{g})$ & $91 \pm 10$ & $89 \pm 10$ \\
\hline
\end{tabular}

Values are presented as mean \pm SEM. No significant differences were documented between treatments (paired $t$ test)

${ }^{\text {a }} \mathrm{mg}$ tocopherol equivalents
GTE and PL capsules were 99 and $98 \%$, respectively). We did not document any dropouts or adverse effects of the supplementation.

After both GTE and PL supplementations, the RST induced a significant increase in plasma lactate concentration (Table 2) and caused the shift of acid-base balance toward metabolic acidosis (a drop in blood $\mathrm{pH}$ and an increase in base deficit and anion gap). The time effect $(p<0.0001)$ was observed in case of all the above-mentioned parameters.

Data regarding the parameters of exercise performance during RST are presented in Table 3. None of the parameters changed significantly after GTE supplementation, as compared to PL supplementation.

A significant increase in resting total plasma polyphenol level (determined with Folin assay) was observed after GTE supplementation, when compared with the respective value recorded after administration of PL $(388 \pm 51.3$ vs. $136 \pm 11.3 \mu \mathrm{g} \mathrm{GE} / \mathrm{ml} ; p<0.01$ ).

The blood levels of oxidative stress and muscle damage markers are presented in Table 4. Significant time $(p<0.001)$, treatment $(p<0.01)$, and time $\times$ treatment interaction effects $(p<0.05)$ on TAC were observed. Only RST performed after PL supplementation caused an increase in TAC level at $5 \mathrm{~min}$, which remained elevated after the 24-h recovery period (both changes were significant as compared to resting value). Similarly to the increase in plasma total polyphenols, elevation of resting plasma TAC was observed after GTE supplementation.

A similar pattern of post-RST changes in plasma UA and AL concentrations was noted after both GTE and PL supplementations (time effect, $p<0.001$ ). Compared to values measured at rest and $5 \mathrm{~min}$ post-exercise, the increase in plasma UA was observed after $24 \mathrm{~h}$ of recovery. An increase in plasma AL was observed 5 min postexercise (as compared to resting values), with subsequent decrease after $24 \mathrm{~h}$ of recovery (as compared to values at 5 min).

Significant time, treatment, and treatment $\times$ time interaction effects (each at $p<0.001$ ) on erythrocyte SOD activity were noted. After the 4-week PL supplementation, the significant increase in erythrocyte SOD activity was documented $5 \mathrm{~min}$ post-exercise (as compared to respective value at rest). The analyzed parameter remained elevated (as compared to resting value) throughout the 24-h recovery period. No significant differences in resting SOD activity were documented between GTE and PL treatment. In turn, comparing to PL, GTE supplementation caused a decrease in SOD activity at $5 \mathrm{~min}$ and $24 \mathrm{~h}$ after RST. Contrary to SOD, no significant changes in GPx activity were noted, either in response to the RST (performed after both GTE and PL supplementations) or as a result of the 4-week GTE supplementation. 
Table 2 Changes in blood indices of acid-base balance and plasma lactate concentration induced by the repeated sprint test $(4 \times 15 \mathrm{~s})$ in sprinters $(n=16)$ after 4-week supplementation with placebo (PL) or green tea extract (GTE)

\begin{tabular}{|c|c|c|c|c|}
\hline & \multicolumn{2}{|l|}{ PL } & \multicolumn{2}{|l|}{ GTE } \\
\hline & Rest & $3 \mathrm{~min}$ & Rest & $3 \mathrm{~min}$ \\
\hline $\mathrm{pH}$ & $7.41 \pm 0.004$ & $7.18 \pm 0.01 * * *$ & $7.42 \pm 0.006$ & $7.17 \pm 0.01 * * *$ \\
\hline Base excess $(\mathrm{mmol} / \mathrm{L})$ & $0.67 \pm 0.18$ & $-16.24 \pm 0.50 * * *$ & $1.04 \pm 0.24$ & $-16.9 \pm 0.50 * * *$ \\
\hline Anion gap (mmol/L) & $15.12 \pm 0.30$ & $30.61 \pm 0.48 * * *$ & $14.79 \pm 0.16$ & $30.26 \pm 0.39 * * *$ \\
\hline Lactate $(\mathrm{mmol} / \mathrm{L})$ & $1.84 \pm 0.12$ & $17.99 \pm 055^{* * *}$ & $1.84 \pm 0.12$ & $18.69 \pm 0.45^{* * *}$ \\
\hline
\end{tabular}

Values are presented as mean \pm SEM. Blood samples were collected before the test (at rest) and 3 min after the test ( 3 min). The data were analyzed using two-way ANOVA: two treatment (placebo and GTE) $\times$ two time points (at rest and 3 min after completion of the test). Time effect was observed for all the analyzed parameters $(p<0.001)$ with no treatment and time $\times$ treatment interactions $(p>0.05)$

*** Significantly different $(p<0.0001)$ from the resting value (Bonferroni test)

Table 3 Changes in the results of the repeated sprint test $(4 \times 15 \mathrm{~s})$ in sprinters $(n=16)$ after 4-week supplementation with placebo (PL) or green tea extract (GTE)

\begin{tabular}{lrr}
\hline & \multicolumn{1}{l}{ PL } & \multicolumn{1}{l}{ GTE } \\
\hline Peak power $^{\mathrm{a}}(\mathrm{W} / \mathrm{kg})$ & $10.68 \pm 0.12$ & $10.86 \pm 0.13$ \\
Mean power $^{\mathrm{a}}(\mathrm{W} / \mathrm{kg})$ & $8,91 \pm 0.08$ & $8.90 \pm 0.09$ \\
Total work output $^{\mathrm{b}}(\mathrm{J} / \mathrm{kg})$ & $533.5 \pm 4.89$ & $533.8 \pm 5.53$ \\
Fatigue index $^{\mathrm{a}}(\%)$ & $11.3 \pm 1.07$ & $12.2 \pm 0.81$ \\
\hline
\end{tabular}

Values are presented as mean \pm SEM. No significant differences were documented between treatments (paired $t$ test)

${ }^{a}$ mean value for four bouts $(4 \times 15 \mathrm{~s})$ of the exercise test

b sum of the values determined during four bouts $(4 \times 15 \mathrm{~s})$ of the exercise test

Both RST and GTE supplementations affected plasma concentration of MDA $(p<0.001$ for both time and treatment effect). Similar to TAC value, plasma MDA increased $5 \mathrm{~min}$ after RST (as compared to resting value), but only after PL administration. However, after $24 \mathrm{~h}$ of recovery, a decrease in plasma MDA (as compared to level at 5 min) was observed after both PL and GTE treatments. As a result of GTE supplementation, a significant decrease in both resting and post-exercise (at $5 \mathrm{~min}$ ) MDA levels was observed.

The RST, performed after both PL and GTE treatments, induced changes in plasma CK activity (time effect, $p<0.001)$. An increase in this parameter was observed after the 24-h recovery period as compared to resting value. No significant differences between PL and GTE treatments were documented at any of the three time points.

\section{Discussion}

To the best of our knowledge, this study is the first one which analyzed the effect of GTE supplementation on oxidative stress in sprint-trained athletes. Our results suggest that supplementation with GTE prevents oxidative stress induced by high-intensity RST conducted in male sprinters.

Oxidative stress may be considered a condition in which the production of ROS exceeds the physiological capacity of the antioxidant system to render ROS inactive [2]. Previous studies showed that lipid radical production increases in response to short-term supramaximal anaerobic exercise [2, 33, 34]. In our study, RST performed after PL treatment enhanced the oxidative damage, since additional accumulation of lipid peroxidation by-products, expressed as plasma MDA, was noted 5 min post-exercise. However, increased plasma MDA, observed post-exercise, was followed by a decrease in plasma MDA during the 24-h recovery. According to some authors, adaptation to elevated hydroperoxide concentration, observed immediately after intense exercise, is associated with a concomitant increase in the antioxidant potential [35]. This acute adaptation includes both enzymatic [36] and non-enzymatic antioxidant systems [36, 37]. Thus, an increase in post-exercise plasma TAC observed in our athletes probably represented an adaptive response to the enhanced generation of ROS. Our finding is consistent with previous studies with the single 30 -s Wingate test $[35,38]$.

Urate, proteins, and ascorbate are major antioxidants of human plasma [39]. Thus, the post-exercise increase in plasma TAC observed in our participants might be influenced, at least partially, by an increase in plasma $\mathrm{AL}$ concentration. Our findings are consistent with the results of a previous study [40], in which higher serum concentration of total AL was documented immediately after intense session of anaerobic exercise. Surprisingly, however, we observed the elevated levels of UA, a major contributor to plasma TAC, $24 \mathrm{~h}$ after RST rather than 5 min post-exercise.

The purine nucleotide system is extremely active during high-intensity exercise and muscle ischemic conditions. This is reflected by the release of hypoxanthine, ammonia, 
Table 4 Changes in blood parameters of oxidative stress and muscle damage induced by the repeated sprint test $(4 \times 15 \mathrm{~s})$ in sprinters $(n=16)$ after 4-week supplementation with placebo (PL) or green tea extract (GTE)

\begin{tabular}{|c|c|c|c|c|c|}
\hline & PL & GTE & Time & Treatment & Time $\times$ treatment \\
\hline \multicolumn{6}{|c|}{ Total antioxidant capacity (TAC) (mmol/L) } \\
\hline Rest & $1.33 \pm 0.04$ & $1.52 \pm 0.03^{*}$ & \multirow[t]{3}{*}{ Yes } & \multirow[t]{3}{*}{ Yes } & \multirow[t]{3}{*}{ Yes } \\
\hline $5 \min$ & $1.58 \pm 0.04 * * *$ & $1.54 \pm 0.04$ & & & \\
\hline $24 \mathrm{~h}$ & $1.51 \pm 0.05^{* *}$ & $1.59 \pm 0.06$ & & & \\
\hline \multicolumn{6}{|c|}{ Uric acid (UA) (mg/dL) } \\
\hline Rest & $5.15 \pm 0.26$ & $4.31 \pm 0.20$ & \multirow[t]{3}{*}{ Yes } & \multirow[t]{3}{*}{ No } & \multirow[t]{3}{*}{ No } \\
\hline $5 \min$ & $5.16 \pm 0.26$ & $4.30 \pm 0.15$ & & & \\
\hline $24 \mathrm{~h}$ & $6.61 \pm 0.29 * * *, \dagger \dagger$ & $6.81 \pm 0.28 * * *, \dagger \dagger$ & & & \\
\hline \multicolumn{6}{|c|}{ Albumin (AL) (g/dL) } \\
\hline Rest & $4.09 \pm 0.14$ & $4.06 \pm 0.10$ & \multirow[t]{3}{*}{ Yes } & \multirow[t]{3}{*}{ No } & \multirow[t]{3}{*}{ No } \\
\hline $5 \min$ & $4.68 \pm 0.18^{* *}$ & $4.89 \pm 0.20 * * *$ & & & \\
\hline $24 \mathrm{~h}$ & $4.20 \pm 0.08^{\dagger}$ & $4.44 \pm 0.14^{\dagger}$ & & & \\
\hline \multicolumn{6}{|c|}{ Superoxide dismutase (SOD) (U/g Hb) } \\
\hline Rest & $1,596.8 \pm 55.7$ & $1,524.0 \pm 28.4$ & \multirow[t]{3}{*}{ Yes } & \multirow[t]{3}{*}{ Yes } & \multirow[t]{3}{*}{ Yes } \\
\hline $5 \mathrm{~min}$ & $1,797.4 \pm 33.9 * * *$ & $1,497.2 \pm 32.5^{*+}$ & & & \\
\hline $24 \mathrm{~h}$ & $1,794.3 \pm 34.3^{* * *}$ & $1,468.8 \pm 25.8^{*+*}$ & & & \\
\hline \multicolumn{6}{|c|}{ Glutathione peroxidase (GPx) (U/g Hb) } \\
\hline Rest & $46.8 \pm 2.2$ & $39.0 \pm 2.1$ & \multirow[t]{3}{*}{ No } & \multirow[t]{3}{*}{ No } & \multirow[t]{3}{*}{ No } \\
\hline $5 \min$ & $38.8 \pm 1.7$ & $37.1 \pm 1.1$ & & & \\
\hline $24 \mathrm{~h}$ & $38.3 \pm 3.2$ & $37.8 \pm 1.9$ & & & \\
\hline \multicolumn{6}{|c|}{ Malondialdehyde (MDA) $(\mu \mathrm{mol} / \mathrm{L})$} \\
\hline Rest & $1.15 \pm 0.09$ & $0.66 \pm 0.04^{*}$ & \multirow[t]{3}{*}{ Yes } & \multirow[t]{3}{*}{ Yes } & \multirow[t]{3}{*}{ No } \\
\hline $5 \min$ & $1.48 \pm 0.08^{* *}$ & $0.85 \pm 0.06^{*+}$ & & & \\
\hline $24 \mathrm{~h}$ & $0.86 \pm 0.09^{\dagger+\dagger}$ & $0.53 \pm 0.02^{\dagger \dagger}$ & & & \\
\hline \multicolumn{6}{|c|}{ Creatine kinase (CK) (U/L) } \\
\hline Rest & $192.0 \pm 18.2$ & $178.1 \pm 15.0$ & \multirow[t]{3}{*}{ Yes } & \multirow[t]{3}{*}{ No } & \multirow[t]{3}{*}{ No } \\
\hline $5 \min$ & $219.5 \pm 18.9$ & $199.0 \pm 17.2$ & & & \\
\hline $24 \mathrm{~h}$ & $230.6 \pm 21.5^{*}$ & $231.5 \pm 19.8^{* *}$ & & & \\
\hline
\end{tabular}

Values are presented as mean \pm SEM. Blood samples were collected before the test (at rest), 5 min after the test (5 min), and after $24 \mathrm{~h}$ of recovery $(24 \mathrm{~h})$. The data were analyzed using two-way ANOVA: two treatment (placebo and GTE) $\times$ three time points (at rest, 5 min, and $24 \mathrm{~h}$ after completion of the test)

$*$, **, *** Significantly different $(p<0.05 ; p<0.01 ; p<0.001$, respectively) from the resting value (within the same treatment; Bonferroni test)

$\dagger+,+\dagger$ Significantly different ( $p<0.01 ; p<0.001$, respectively) from the value determined at 5 min (within the same treatment; Bonferroni test)

\#, + , ⿰木木 Significantly different $(p<0.05 ; p<0.01 ; p<0.001$, respectively) from the respective value determined after placebo treatment (Bonferroni test)

and UA into the circulation. Consequently, increased plasma UA documented in our athletes at $24 \mathrm{~h}$ after RST may reflect the enhancement of energy-rich purine phosphates catabolism and contribution of a XO to the free radical generating system [41]. On the other hand, although UA is the end product of the purine nucleotide degradation, it may be an important scavenger of free radicals in human plasma and in skeletal muscle during and after acute exercise [42]. This may be a potential reason for the lack of increase in plasma UA documented in our participants 5 min post-exercise, since circulating UA was postulated to be taken up by the recovering muscle, and serve as a free oxygen radical scavenger [43]. Baker et al. [38] reported a significant decrease in serum UA immediately after the 30-s Wingate test; this was followed by an increase in serum UA and concomitant decrease in serum lipid hydroperoxide and MDA concentrations $24 \mathrm{~h}$ post-exercise. Thus, elevated plasma levels of UA and TAC, observed during the recovery period of our study, were likely responsible for the attenuation of oxidative damage; this hypothesis is supported by decreased plasma MDA levels documented during the recovery period.

In the present study, RST performed after PL treatment caused a rise in erythrocyte SOD activity, in parallel to the 
above-mentioned reinforced non-enzymatic antioxidant potential of plasma. In another study [36], an increase in blood activity of the antioxidant enzymes (inter alia SOD and GPx) was noted in untrained men after a single boot of both maximal and submaximal exercises. However, we did not observe changes in erythrocyte GPx activity, which should be addressed in future studies.

There is some evidence that antioxidant supplementation could protect from exercise-induced muscular and oxidative damage, inflammation, muscle force loss, and fatigue [44]. This protection might accelerate recovery and, in turn, lead to increased exercise performance. In the present study, polyphenols of GTE contributed to an elevated resting plasma TAC. On the other hand, GTE supplementation prevented increase in post-exercise plasma TAC. Our observations are consistent with the results of another study [45], in which polyphenol-rich dark chocolate turned out to blunt the exercise-induced increase in plasma TAC. In our study, post-exercise plasma levels of TAC and MDA remained unchanged solely after GTE treatment. In contrast, an increase in both these parameters was observed 5 min after RST performed after PL treatment. These observations suggest that GTE supplementation may protect sprinters against oxidative stress induced by acute RST, by enhancing antioxidant defense at rest. In our previous study including previously untrained men who were subjected to a 4-week strength training [16], GTE supplementation protected against oxidative stress induced by acute muscular endurance test, as well as against muscular damage induced by the training alone. Similar observations were reported by Panza et al. [17], in a group of resistance-trained men. In both cited studies, significant decrease in post-exercise plasma $\mathrm{CK}$ activity was noted as a result of supplementation. However, in our present study, GTE supplementation provided no protection from exercise-induced muscle damage. On the other hand, a number of previous studies [6, 10,46] revealed intensified muscle damage and hindered recovery as a result of antioxidant supplementation. Moreover, according to several authors [7, 9, 22], antioxidant supplementation may prevent some cellular adaptations to sport training. In view of our hereby presented findings, GTE intake is unlikely to affect sprint training adaptation, as resting SOD activity did not differ between PL and GTE treatments. In turn, the blunting effect of GTE supplementation on SOD activity postexercise and after 24-h recovery was observed in our study, which strongly points to diminished production of superoxide anions [34]. Finally, green tea catechins were identified as a potential inhibitor of XO [25]. Although we did not measure plasma XO activity, no changes in plasma UA (the end product XO system) were noted after GTE supplementation. Recently, normal adaptations to exercise were observed in rats despite protection against oxidative stress resulting from long-term supplementation with large doses of antioxidant vitamins [12] or treatment with allopurinol as XO inhibitor [47]. Thus, our study showed that supplementation with GTE does not interfere with training adaptation of antioxidant enzyme system. Although GTE prevented exercise-induced oxidative stress, it neither modulated plasma CK activity nor affected the result of RST. This suggests that GTE supplementation neither protects against muscle damage nor improves repeated sprint performance in male sprinters.

The fact that the same athletes received both PL and GTE capsules represents a strength of the present study, especially in view of considerable individual variation in analyzed biomarkers. However, the fact that we used MDA, rather than more specific parameters recommended by EFSA [48], e.g., $F_{2}$-isoprostanes, as a marker of lipid peroxidation can be potential limitation of our study. Similarly, determination of other antioxidants contributing to total antioxidant potential of the plasma, such as vitamin $\mathrm{C}$ or selected flavanols, could provide more accurate information on the response of antioxidant defense to acute exercise or GTE supplementation.

In conclusion, supplementation with GTE prevents oxidative stress induced by high-intensity repeated sprint test in male sprinters. On the other hand, neither protection from exercise-induced muscle damage, nor an improvement in sprint performance was noted after GTE intake. Our findings suggest that GTE intake is likely not beneficial in the case of sprinters, at least during the preparatory phase of their yearly training cycle. The effects of GTE supplementation during the competition phase of yearly training cycle, being associated with markedly greater exercise load, should be a subject of future research.

Acknowledgments The study was financed by the project of University of Physical Education BW/III/27.

Open Access This article is distributed under the terms of the Creative Commons Attribution License which permits any use, distribution, and reproduction in any medium, provided the original author(s) and the source are credited.

\section{References}

1. Powers SK, Ji LL, Leeuwenburgh C (1999) Exercise traininginduced alterations in skeletal muscle antioxidant capacity: a brief review. Med Sci Sports Exerc 31(7):987-997

2. Bloomer RJ, Goldfarb AH (2004) Anaerobic exercise and oxidative stress: a review. Can J Appl Physiol 29(3):245-263

3. Murrant CL, Reid MB (2001) Detection of reactive oxygen and reactive nitrogen species in skeletal muscle. Microsc Res Tech 55(4):236-248

4. Gomez-Cabrera MC, Domenech E, Viña J (2008) Moderate exercise is an antioxidant: upregulation of antioxidant genes by training. Free Radic Biol Med 44(2):126-131 
5. Teixeira V, Valente H, Casal S, Marques F, Moreira P (2009) Antioxidant status, oxidative stress, and damage in elite trained kayakers and canoeists and sedentary controls. Int J Sport Nutr Exerc Metab 19(5):443-456

6. Close GL, Ashton T, Cable T, Doran D, Holloway C, McArdle F, MacLaren DP (2006) Ascorbic acid supplementation does not attenuate post-exercise muscle soreness following muscle-damaging exercise but may delay the recovery process. Br J Nutr 95(5):976-981

7. Khassaf M, McArdle A, Esanu C, Vasilaki A, McArdle F, Griffiths RD, Brodie DA, Jackson MJ (2003) Effect of vitamin C supplements on antioxidant defence and stress proteins in human lymphocytes and skeletal muscle. J Physiol 549(Pt 2):645-652

8. Gomez-Cabrera MC, Domenech E, Romagnoli M, Arduini A, Borras C, Pallardo FV, Sastre J, Viña J (2008) Oral administration of vitamin $\mathrm{C}$ decreases muscle mitochondrial biogenesis and hampers training-induced adaptations in endurance performance. Am J Clin Nutr 87(1):142-149

9. Strobel NA, Peake JM, Matsumoto A, Marsh SA, Coombes JS, Wadley GD (2011) Antioxidant supplementation reduces skeletal muscle mitochondrial biogenesis. Med Sci Sports Exerc 43(6): 1017-1024

10. Teixeira VH, Valente HF, Casal SI, Marques AF, Moreira PA (2009) Antioxidants do not prevent postexercise peroxidation and may delay muscle recovery. Med Sci Sports Exerc 41(9):1752-1760

11. Yfanti $C$, Akerström $T$, Nielsen $S$, Nielsen $A R$, Mounier $R$, Mortensen OH, Lykkesfeldt J, Rose AJ, Fischer CP, Pedersen BK (2010) Antioxidant supplementation does not alter endurance training adaptation. Med Sci Sports Exerc 42(7):1388-1395

12. Higashida K, Kim SH, Higuchi M, Holloszy JO, Han DH (2011) Normal adaptations to exercise despite protection against oxidative stress. Am J Physiol Endocrinol Metab 301(5):779-784

13. Gross M, Baum O, Hoppeler H (2011) Antioxidant supplementation and endurance training: win or loss? Eur J Sport Sci 11(1):27-32

14. Nikolaidis MG, Kerksick CM, Lamprecht M, McAnulty SR (2012) Does vitamin C and E supplementation impair the favorable adaptations of regular exercise? Oxid Med Cell Longev 707941. doi:10.1155/2012/707941

15. Zaveri NT (2006) Green tea and its polyphenolic catechins: medicinal uses in cancer and noncancer applications. Life Sci 78(18):2073-2080

16. Jówko E, Sacharuk J, Balasińska B, Ostaszewski P, Charmas M, Charmas R (2011) Green tea extract supplementation gives protection against exercise-induced oxidative damage in healthy men. Nutr Res 31(11):813-821

17. Panza VS, Wazlawik E, Ricardo Schütz G, Comin L, Hecht KC, da Silva EL (2008) Consumption of green tea favorably affects oxidative stress markers in weight-trained men. Nutrition 24(5):433-442

18. Ji LL (1999) Antioxidants and oxidative stress in exercise. Proc Soc Exp Biol Med 222(3):283-292

19. Sachdev S, Davies KJ (2008) Production, detection, and adaptive responses to free radicals in exercise. Free Radic Biol Med 44(2):215-223

20. Abbey EL, Rankin JW (2011) Effect of quercetin supplementation on repeated-sprint performance, xanthine oxidase activity, and inflammation. Int J Sport Nutr Exerc Metab 21(2):91-96

21. Gómez-Cabrera MC, Pallardó FV, Sastre J, Viña J, García-delMoral L (2003) Allopurinol and markers of muscle damage among participants in the Tour de France. JAMA 289(19):2503-2504

22. Gomez-Cabrera MC, Borrás C, Pallardó FV, Sastre J, Ji LL, Viña J (2005) Decreasing xanthine oxidase-mediated oxidative stress prevents useful cellular adaptations to exercise in rats. J Physiol 567(Pt 1):113-120
23. Kang C, O’Moore KM, Dickman JR, Ji LL (2009) Exercise activation of muscle peroxisome proliferator-activated receptorgamma coactivator-1alpha signaling is redox sensitive. Free Radic Biol Med 47(10):1394-1400

24. Kashima M (1999) Effects of catechins on superoxide and hydroxyl radical. Chem Pharm Bull (Tokyo) 47(2):279-283

25. Aucamp J, Gaspar A, Hara Y, Apostolides Z (1997) Inhibition of xanthine oxidase by catechins from tea (Camellia sinensis). Anticancer Res 17(6D):4381-4385

26. Brown AL, Lane J, Holyoak C, Nicol B, Mayes AE, Dadd T (2011) Health effects of green tea catechins in overweight and obese men: a randomised controlled cross-over trial. Br J Nutr 106(12):1880-1889

27. Szponar L, Wolnicka K, Rychlik E (2000) Album of photographs of food products and dishes. National Food and Nutrition Institute, Warsaw (in Polish)

28. Kunachowicz H, Nadolna I, Przygoda B, Iwanow K (2005) Tabele składu i wartosci odzywczej zywnosci. PZWL, Warsaw (in Polish)

29. Maskarinec G, Chan CLY, Meng L, Franke AA, Cooney RV (1999) Exploring the feasibility and effects of a high-fruit and vegetable diet in healthy women. Cancer Epidemiol Biomarkers Prev 8:919-924

30. Baker JS, Williams SR, Whitcombe D, Davies B (2007) Plasma volume response to 30-s cycle ergometry: influence on lipid and lipoprotein. Med Sci Sports Exerc 39(9):1579-1586

31. Dill DB, Costill DL (1974) Calculation of percentage changes in volumes of blood, plasma and red blood cells in dehydration. J Appl Physiol 37:247-248

32. Ziemlanski S (2001) Norm of man's nutrition. PZWL, Warsaw

33. Marzatico F, Pansarasa O, Bertorelli L, Somenzini L, Della Valle G (1997) Blood free radical antioxidant enzymes and lipid peroxides following long-distance and lactacidemic performances in highly trained aerobic and sprint athletes. J Sports Med Phys Fitness 37(4):235-239

34. Groussard C, Rannou-Bekono F, Machefer G, Chevanne M, Vincent S, Sergent O, Cillard J, Gratas-Delamarche A (2003) Changes in blood lipid peroxidation markers and antioxidants after a single sprint anaerobic exercise. Eur J Appl Physiol 89(1):14-20

35. Taito S, Oyama F, Takahashi M, Sekikawa K, Inamizu T (2010) Changes in plasma oxidative stress biomarkers after single-sprint anaerobic exercise. Adv Exer Sports Physiol 16(1):7-13

36. Berzosa C, Cebrián I, Fuentes-Broto L, Gómez-Trullén E, Piedrafita E, Martínez-Ballarín E, López-Pingarrón L, Reiter RJ, García JJ (2011) Acute exercise increases plasma total antioxidant status and antioxidant enzyme activities in untrained men. J Biomed Biotechnol. doi:10.1155/2011/540458

37. Hammouda O, Chtourou H, Chaouachi A, Chahed H, Ferchichi S, Kallel C, Chamari K, Souissi N (2012) Effect of short-term maximal exercise on biochemical markers of muscle damage, total antioxidant status, and homocysteine levels in football players. Asian J Sports Med 3(4):239-246

38. Baker JS, Bailey DM, Hullin D, Young I, Davies B (2004) Metabolic implications of resistive force selection for oxidative stress and markers of muscle damage during $30 \mathrm{~s}$ of high-intensity exercise. Eur J Appl Physiol 92(3):321-327

39. Wayner DD, Burton GW, Ingold KU, Barclay LR, Locke SJ (1987) The relative contributions of vitamin E, urate, ascorbate and proteins to the total peroxyl radical-trapping antioxidant activity of human blood plasma. Biochim Biophys Acta 924(3):408-419

40. Çolak T, Bamaç B, Çolak S, Duman C, Bayazit B et al (2010) The influence of a single bout of wrestling exercise on serum levels of ischemia-modified albumin. J Exerc Sci Fitness 8(2):67-72 
41. Ascensão A, Rebelo A, Oliveira E, Marques F, Pereira L, Magalhães J (2008) Biochemical impact of a soccer match - analysis of oxidative stress and muscle damage markers throughout recovery. Clin Biochem 41(10-11):841-851

42. Waring WS, Convery A, Mishra V, Shenkin A, Webb DJ, Maxwell SR (2003) Uric acid reduces exercise-induced oxidative stress in healthy adults. Clin Sci (Lond) 105(4):425-430

43. Stathis CG, Carey MF, Snow RJ (2005) The influence of allopurinol on urinary purine loss after repeated sprint exercise in man. Metabolism 54(10):1269-1275

44. Howatson G, van Someren KA (2008) The prevention and treatment of exercise-induced muscle damage. Sports Med 38(6):483-503

45. Davison G, Callister R, Williamson G, Cooper KA, Gleeson M (2012) The effect of acute pre-exercise dark chocolate consumption on plasma antioxidant status, oxidative stress and immunoendocrine responses to prolonged exercise. Eur J Nutr 51(1):69-79

46. Avery NG, Kaiser JL, Sharman MJ, Scheett TP, Barnes DM, Gómez AL, Kraemer WJ, Volek JS (2003) Effects of vitamin E supplementation on recovery from repeated bouts of resistance exercise. J Strength Cond Res 17(4):801-809

47. Wadley GD, Nicolas MA, Hiam D, McConell GK (2013) Xanthine oxidase inhibition attenuates skeletal muscle signaling following acute exercise but does not impair mitochondrial adaptations to endurance training. Am J Physiol Endocrinol Metab 304(8):853-862

48. EFSA Panel on Dietetic Products, Nutrition and Allergies (NDA) (2011) Guidance on the scientific requirements for health claims related to antioxidants, oxidative damage and cardiovascular health. EFSA J 9(12): 2474. [13 pp.]. doi:10.2903/j.efsa.2011. 2474. www.efsa.europa.eu/efsajournal 